\title{
Social inclusion and higher education
}

Basit, T \& Tomlinson, S Eds. (2012). Social inclusion and higher education. Bristol: The Policy Press.

Recent decades have witnessed a dramatic increase in the number of students coming to higher education from different backgrounds. These students, variously termed "nontraditional" or "disadvantaged" have certainly changed the landscape of university classes, campuses and graduation ceremonies. The effects of higher education on lifetime income and social status are fairly well researched but there has been a knowledge gap around these students' experiences while they are at university. This book goes some way to address that gap.

The collection, admirably edited by Tehmina N. Basit and Sally Tomlinson, brings together a range of case studies from the United Kingdom, United States and Australia that highlight the problems that these students face and how they might be better addressed for student success. The various chapters explore the dimensions of gender, ethnicity, socioeconomic status and culture and the complex intersections they generate. This is a both engaging and practical book. It offers a helicopter overview of different countries and different student groups as well as detailed insights into lived experiences of students and their families and strategies that have been developed and used by students and higher education institutions to improve student success.

The book is divided into two parts. The first section explores more theoretical issues in social inclusion with various authors unpacking notions of ethnicity, capital, gender, social justice as they relate to higher education. Chapter two provides an insightful UK historical perspective while two chapters from Australia offer critical analyses of higher education policies. Several themes resonate in this section of the book - the tensions between equity and merit, the subsuming of social justice oriented policy by economic imperatives as well as the complex array of factors that impact on student participation and success.

In the second section, more empirical studies of widening participation are reported. Here the voices of students from ethnic minorities, Indigenous Australians and women powerfully come through the research reported. There is also strategy in these chapters. These range across how students perceive and receive feedback to the ways in which partnerships can enhance student experience and our higher education practices.

Overall the book gives us insights that students and their families are finding ways of acquiring capital and developing self esteem. In a myriad of ways students' 
personal resources and universities' more effective strategies encourage and sustain their participation in higher education. It would appear that the issues surrounding the inclusion of 'non-traditional' students are largely comparable in different countries thus making this collection a useful resource internationally. It will be constructive to leaders, managers and teachers in institutions of higher education as well as students or potential students from all backgrounds.

\section{Lesley Chenoweth}

Professor and Head, Logan Campus

Griffith University 